\title{
Centrifugal SHS-metallurgy of nitrogen steels
}

\author{
V. I. Yukhvid, D. M. Ikornikov, D. E. Andreev ${ }^{\dagger}$, V. N. Sanin, M. I. Alymov, N. V. Sachkova, \\ V.N. Sememova, I. D. Kovalev \\ †ade@ism.ac.ru
}

A. G. Merzhanov Institute of Structural Macrokinetics of RAS, 8 Akademika Osipyana str., Chernogolovka, 142432, Russia

The possibility of obtaining alloyed nitrogen steel by centrifugal SHS-metallurgy at atmospheric pressure is shown. The initial mixture for obtaining alloyed cast steel included iron, manganese, nickel, molybdenum, vanadium and silicon oxides, as well as aluminum, chromium and chromium nitride. The experimental studies were carried out in a centrifugal installation under overloading ( $a$ ) of $1-50 \mathrm{~g}$. It is shown that at $a=1 \mathrm{~g}$ combustion is accompanied by a significant scattering of the mixture. In the case of overloading, the scattering is suppressed. The combustion products, steel and slag, are in cast state and divided into two layers; they have practically no adhesion. The mixture combustion is accompanied by intensive convective mixing of the combustion products. Gravitational convection of the two-phase melt above the combustion front and bubbling of the gaseous products provides intensive mixing, ensure high completeness of the chemical transformation of the initial mixture, and uniformity of the steel composition. Most of the experiments were carried out at $a=50 \mathrm{~g}$. It is shown that in the ranges of Cr and $\mathrm{Cr}_{2} \mathrm{~N}$ concentrations under study, the mixtures retain the ability to burn and are well separated. Introduction of chromium nitride into the initial mixture makes it possible to obtain nitrogen steel with a nitrogen content of up to $0.3-0.4$ wt. $\%$. According to X-ray phase analysis, this steel has $\gamma$-Fe lattice. The displacement of the peaks and their broadening indicate the dissolution of the alloying elements in $\gamma$-Fe. Steel has a grain structure with narrow grain boundaries. Point inclusions concentrated in the grains and at the boundaries were also detected. The analysis of the elemental distribution and structural components composition proves that the steel base is formed by $\mathrm{Cr}$, Mn and Ni solution in Fe, narrow boundaries between the grains are formed by Fe, Mn, Mo and V solution in Cr. Point inclusions mainly contain Mn and Mo.

Keywords: nitrogen steel, centrifugal SHS-metallurgy, combustion, chemical transformation, gravity separation.

\section{Introduction}

One of the important tasks for development of the Arctic region is creation of new steels and technologies for their production. One of the most promising directions is the development of cost-effective alloyed cold-resistant steels with high strength, operating at temperatures lower than $-30^{\circ} \mathrm{C}$. The main alloying elements in the steel are $\mathrm{Cr}$, $\mathrm{Mn}$, Ni. Besides, small additions of $\mathrm{Si}, \mathrm{Mo}$, V, etc., which substantially increase the steel strength at low temperatures, can be introduced into the cold-resistant steels $[1,2]$. The steel is most strongly embrittled by S, P and C impurities, so low-carbon alloyed steels with a low $\mathrm{S}$ and $\mathrm{P}$ content are of great interest for practical application.

It has been found out that introduction of nitrogen into steel reduces brittleness and increases its cold resistance [3-11]. The solubility of nitrogen in steel at atmospheric pressure does not exceed $0.3 \mathrm{wt} \%$. Corrosion-resistant steels of martensitic (with nitrogen content of up to $0.1 \%$ ) and austenitic-martensitic (with nitrogen content of up to $0.15 \%$ ) types are melted in open induction or arc furnaces at atmospheric pressure. To achieve a higher nitrogen content, new equipment has been developed that allows melting under nitrogen pressure $[12,13]$. Nitrogen gas or nitrogencontaining alloy (metal nitrides or nitrogen ferroalloys) are used to introduce nitrogen into steel, as a rule. There is also an approach that uses the aluminothermic process under nitrogen pressure and additives of nitrogen-containing alloy [14].

Self-propagating high-temperature synthesis (SHS) is widely used for obtaining metal nitrides and nitrogen ferroalloys [15]. Nowadays the scientific-technical production enterprise Etalon (Magnitogorsk) has established a multi-tonnage SHS-production of nitrogen ferroalloys [16] and uses metal powders, ferroalloys and gaseous nitrogen as starting materials. One of the promising directions is SHS-metallurgy. It allows obtaining a wide range of cast composite materials, items and protective coatings. SHSmetallurgy uses mixtures of metal oxides with nonmetals and active reducing elements [17-19]. Aluminum nitride was also has been introduced into initial mixtures under high gas pressure to obtain oxynitride ceramics (AlON) by SHS-metallurgy [20]. High combustion temperature of initial mixtures leads to intense gas generation and melt scattering at atmospheric pressure. High pressure and centrifugal action can suppress the scattering, so SHS-metallurgy process carried out in reactors under gas pressure or in centrifugal installations.

This work studies the possibility of nitrogen introduction into metal melts and production of alloyed nitrogencontaining steel by SHS-metallurgy at atmospheric pressure, influence of centrifugal action on the process of autowave chemical transformation, and formation of the steel structure and composition. 


\section{Experimental methods}

The initial mixture for obtaining alloyed cast steel included iron, manganese, nickel, molybdenum, vanadium and silicon oxides, as well as aluminum, chromium and chromium nitride. The experimental studies were carried out in a centrifugal installation under overloading $(a)$ of $1-50 g$ (here $g$ - free fall acceleration). Mixtures of $100 g$ were burned in graphite moulds of $40 \mathrm{~mm}$ in diameter. The experimental procedure is described thoroughly in previous publications $[18,19]$. During the experiments, the linear burning rate $(u)$, the relative mass loss during the combustion $\left(\eta_{1}\right)$ and the completeness of the target element yield in the ingot $\left(\eta_{2}\right)$ were determined. The characteristics were calculated using the formulas: $u=h / t_{c}, \quad \eta_{1}=\left[\left(m_{1}-m_{2}\right) / m_{1}\right] 100 \%$, $\eta_{2}=\left(\mathrm{m} / \mathrm{m}_{c}\right) 100 \%$, where $h$ is the height of the initial mixture layer, $t_{c}$ is the burning time of the layer, $m_{1}$ and $m_{2}$ are the masses of the initial mixture and combustion products, $m$ and $m_{c}$ are the experimental and calculated mass of the ingot.

To investigate the structure and chemical composition of the products, Carl Zeiss Ultra plus high-resolution SEM based on Ultra 55 was used. The phase composition of the final products was determined using DRON-3M diffractometer; the radiation source was an X-ray tube of the BSV-27 type with a copper anode $(\lambda=1.54178 \AA$ ). Nitrogen content was determined by Kjeldahl method.

\section{Experimental results}

For the experiments, the base composition was worked out with the target product being alloyed steel (Table 1).

To prepare the nitrogen steel, an additive comprising a combination of $\mathrm{Cr}_{2} \mathrm{~N}$ and $\mathrm{Cr}$ : $\mathrm{BS}+X(\mathrm{Cr})+Y\left(\mathrm{Cr}_{2} \mathrm{~N}\right)$ was added to the base mixture. The variation of the mass ratio of
$\mathrm{Cr}_{2} \mathrm{~N}$ and $\mathrm{Cr}$ allowed changing the nitrogen content in the steel, keeping the chromium content constant. The calculated composition of steels with different contents of nitrogen and initial mixtures for their production are given in Table 2.

\section{Combustion regularities}

The effect of overloading on $\mathrm{Fe}_{2} \mathrm{O}_{3} / \mathrm{MnO} / \mathrm{NiO} / \mathrm{MoO}_{3} / \mathrm{V}_{2} \mathrm{O}_{5}$ $/ \mathrm{SiO}_{2} / \mathrm{Al} / \mathrm{Cr}$ mixture combustion (1) (Table 2) was studied in the experiments; the chemical conversion product is steel alloyed by $\mathrm{Cr}, \mathrm{Mn}, \mathrm{Ni}, \mathrm{Mo}, \mathrm{V}$ and $\mathrm{Si}$. The study shows that at $a=1 g$ the combustion is accompanied by a strong scattering of the mixture, and the overloading suppresses the scattering (Table 3). The combustion products of steel and slag are in the cast state.

At $a=1 g$, they are poorly separated, and at $a=50 g-$ they are divided into 2 layers and have practically no adhesion. Subsequently, all the experiments were carried out with overloading of $a=50 \mathrm{~g}$. It is shown that in the ranges of $\mathrm{Cr}$ and $\mathrm{Cr}_{2} \mathrm{~N}$ concentrations under study, the mixtures retain the ability to burn and are well separated.

\section{Formation of steel composition and structure}

The influence of $\mathrm{Cr}_{2} \mathrm{~N}$ content on the integral chemical and phase composition of steel (Figs. 1 and 2), its structure (Fig. 3), and structural components composition is shown in Fig. 4 and in Table 4 .

With an increase in $\mathrm{Cr}_{2} \mathrm{~N}$ content in the initial mixture $(Y)$, the nitrogen content in the steel increases to $0.3-0.4 \mathrm{wt} \%$, and then does not change (Fig. 1). It should be noted that the experimental data of the content of $\mathrm{N}$ for $Y \geq 3.4$ and $\mathrm{Mn}$ for $0 \leq Y \leq 13.3$ (Fig. 1) are much lower than the calculated values shown in Table 2. The data of all other elements content in

Table 1. The calculated composition of the base mixture (BM) and steel.

\begin{tabular}{|c|c|c|c|c|c|c|c|c|c|c|c|c|}
\hline \multicolumn{9}{|c|}{ Base mixture, wt \% } & \multicolumn{4}{c|}{ Steel composition, wt \% } \\
\hline $\mathrm{Fe}_{2} \mathrm{O}_{3}$ & $\mathrm{Al}$ & $\mathrm{MnO}_{2}$ & $\mathrm{NiO}$ & $\mathrm{MoO}_{3}$ & $\mathrm{~V}_{2} \mathrm{O}_{5}$ & $\mathrm{SiO}_{2}$ & $\mathrm{Fe}$ & $\mathrm{Mn}$ & $\mathrm{Ni}$ & $\mathrm{Mo}$ & $\mathrm{V}$ & $\mathrm{Si}$ \\
\hline 51.3 & 25.7 & 14.7 & 6.8 & 0.7 & 0.3 & 0.5 & 70.0 & 18.3 & 10.0 & 1.0 & 0.3 & 0.4 \\
\hline
\end{tabular}

Table 2. Effect of the ratio of $\mathrm{Cr}$ and $\mathrm{Cr}_{2} \mathrm{~N}(\alpha)$ on the integral chemical composition of steel.

\begin{tabular}{|c|c|c|c|c|c|c|c|c|}
\hline \multirow{2}{*}{ Initial mixture composition, wt $\%$} & \multicolumn{8}{|c|}{ Steel composition, wt \% } \\
\hline & $\mathrm{Fe}$ & $\mathrm{Cr}$ & $\mathrm{Mn}$ & $\mathrm{Ni}$ & Mo & $\mathrm{V}$ & $\mathrm{Si}$ & $\mathrm{N}$ \\
\hline 1. $\mathrm{BM}-88.3 ; X-11.7 ; Y-0$ & The balance & 20.5 & 14.5 & 7.9 & 0.8 & 0.2 & 0.3 & 0 \\
\hline 2. $\mathrm{BM}-88.3 ; X-8.3 ; Y-3.4$ & The balance & 20.5 & 14.5 & 7.9 & 0.8 & 0.2 & 0.3 & 0.7 \\
\hline 3. $\mathrm{BM}-88.3 ; X-5.0 ; Y-6.7$ & The balance & 20.5 & 14.5 & 7.9 & 0.8 & 0.2 & 0.3 & 1.4 \\
\hline 4. $\mathrm{BM}-88.3 ; X-1.6 ; Y-10.1$ & The balance & 20.5 & 14.5 & 7.9 & 0.8 & 0.2 & 0.3 & 2.1 \\
\hline 5. BM $-86.7 ; X-0 ; Y-13.3$ & The balance & 20.5 & 14.5 & 7.9 & 0.8 & 0.2 & 0.3 & 2.8 \\
\hline
\end{tabular}

Table 3. Effect of $a / g$ on combustion parameters. Initial mixture: $\mathrm{BM}-88.3 ; X-11.7 ; Y-0$.

\begin{tabular}{|c|c|c|c|}
\hline$a / g$ & $u, \mathrm{~cm} / \mathrm{s}$ & $\eta_{1}, \mathrm{wt} \%$ & $\eta_{2}, \mathrm{wt} \%$ \\
\hline 1 & 0.1 & 30.0 & 0 \\
\hline 50 & 4.5 & 4.1 & 73.5 \\
\hline
\end{tabular}




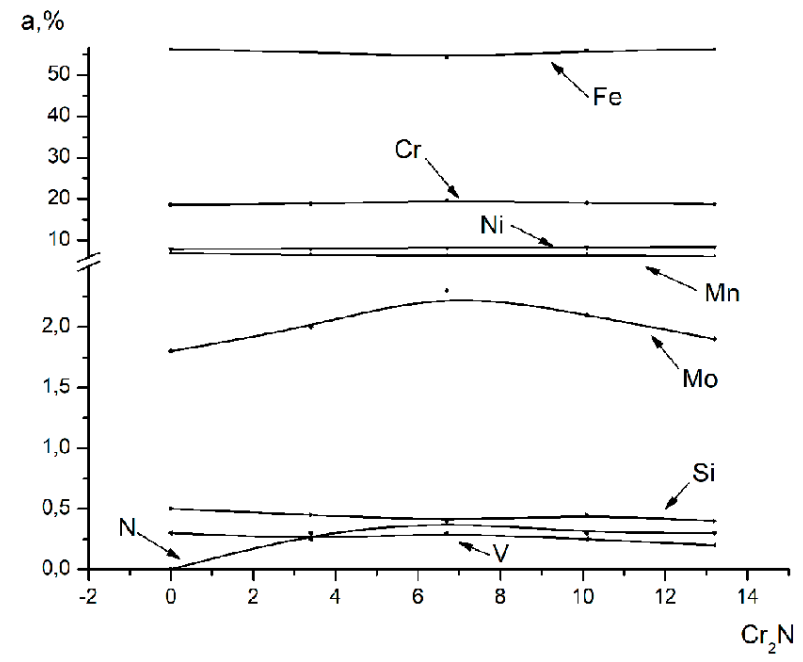

Fig. 1. Effect of $\mathrm{Cr}_{2} \mathrm{~N}$ on steel composition. Initial mixture:

$X\left(\mathrm{Fe}_{2} \mathrm{O}_{3} / \mathrm{MnO} / \mathrm{NiO} / \mathrm{MoO}_{3} / \mathrm{V}_{2} \mathrm{O}_{5} / \mathrm{SiO}_{2} / \mathrm{Al}\right)+\mathrm{YCr}+Z \mathrm{Cr}_{2} \mathrm{~N}$, where $\alpha \mathrm{Cr}_{2} \mathrm{~N}=m\left(\mathrm{Cr}_{2} \mathrm{~N}\right) / m\left(\mathrm{Cr}_{2} \mathrm{~N}\right)+m(\mathrm{Cr}) 100 \%$.

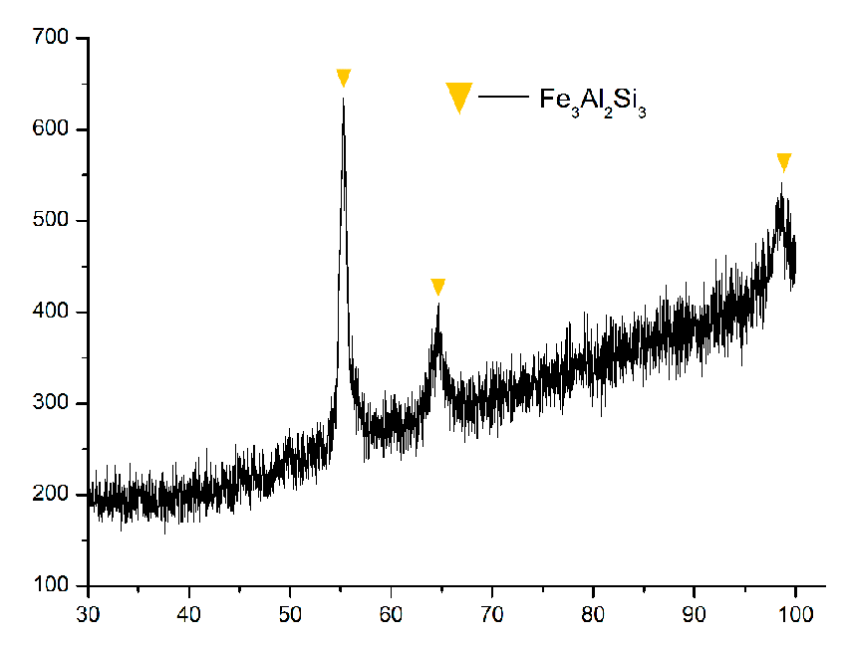

Fig. 2. Steel X-ray pattern. Initial mixture: Base mixture $(\mathrm{BM})-88.3$; $X-5.0 ; Y-6.7$.

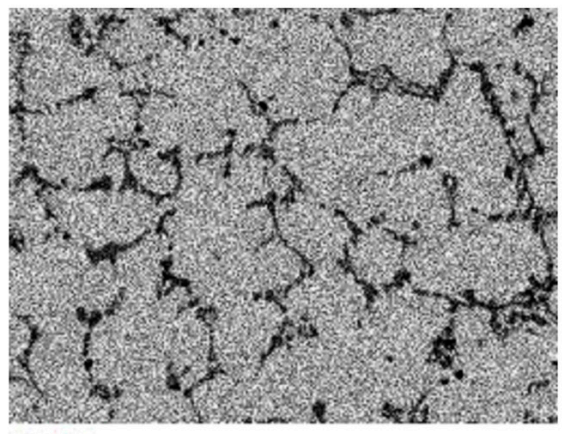

Fe Ka1

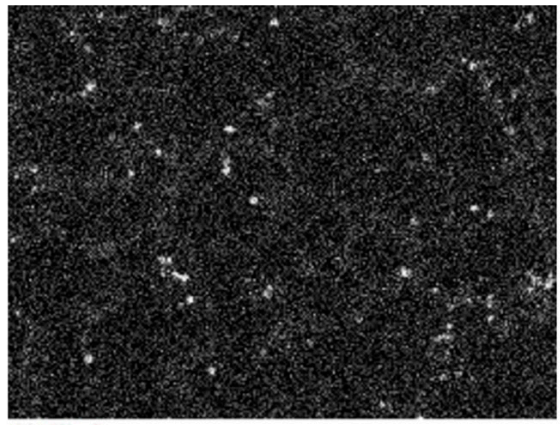

Mn Ka1

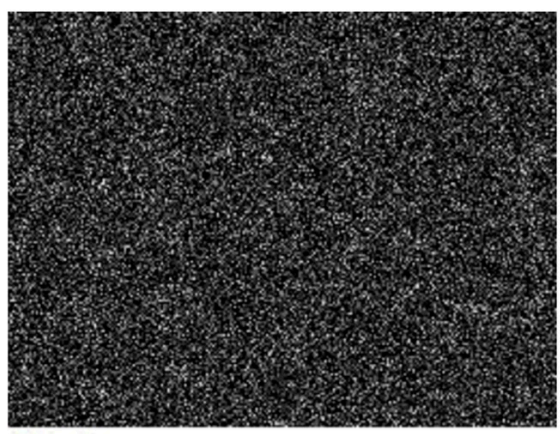

VKa1
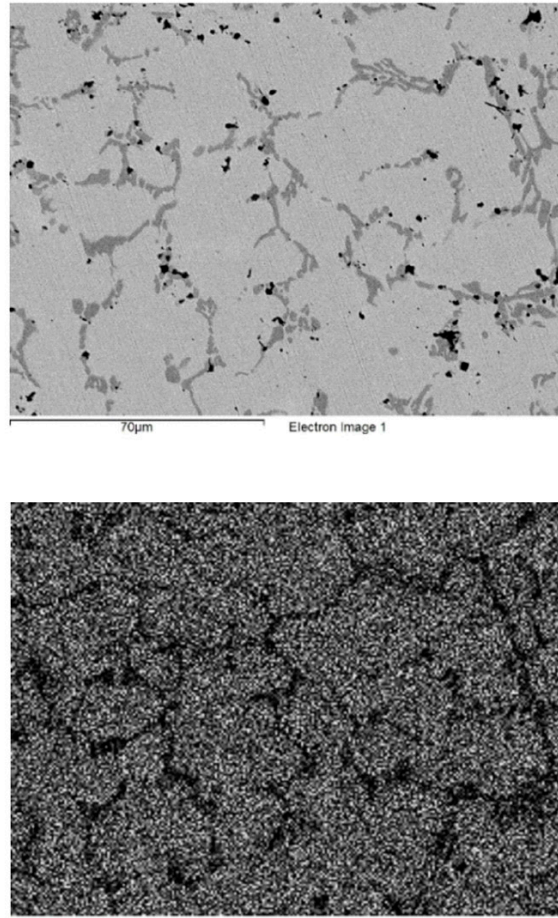

Ni Ka1

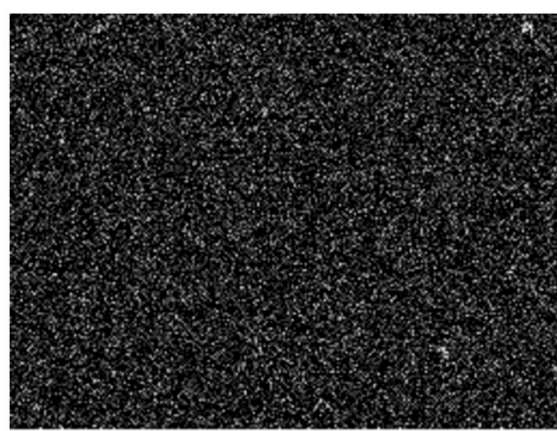

NKa1 2

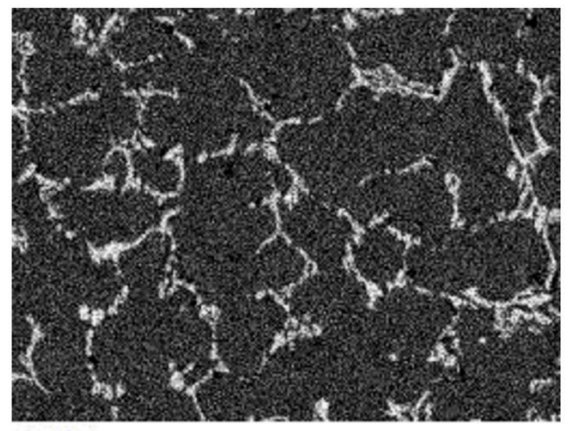

Cr Ka1

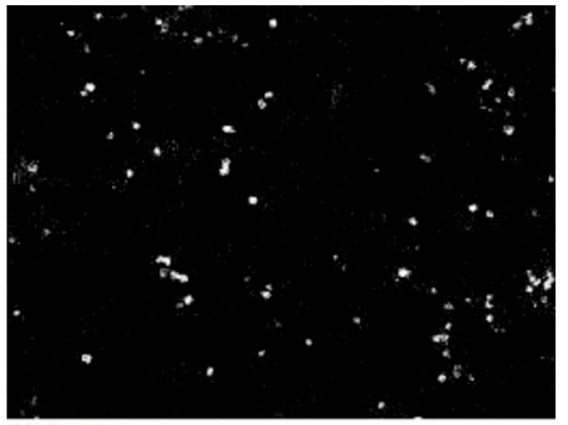

Mo La1

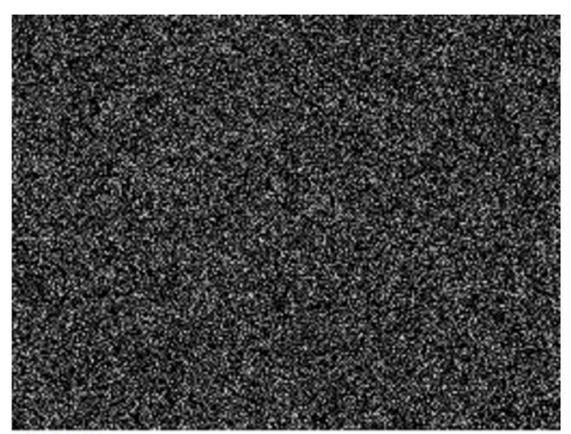

Si Ka1

Fig. 3. Basic elements distribution in steel. Initial mixture: Base mixture (BM) $-88.3 ; X-5.0 ; Y-6.7$. 


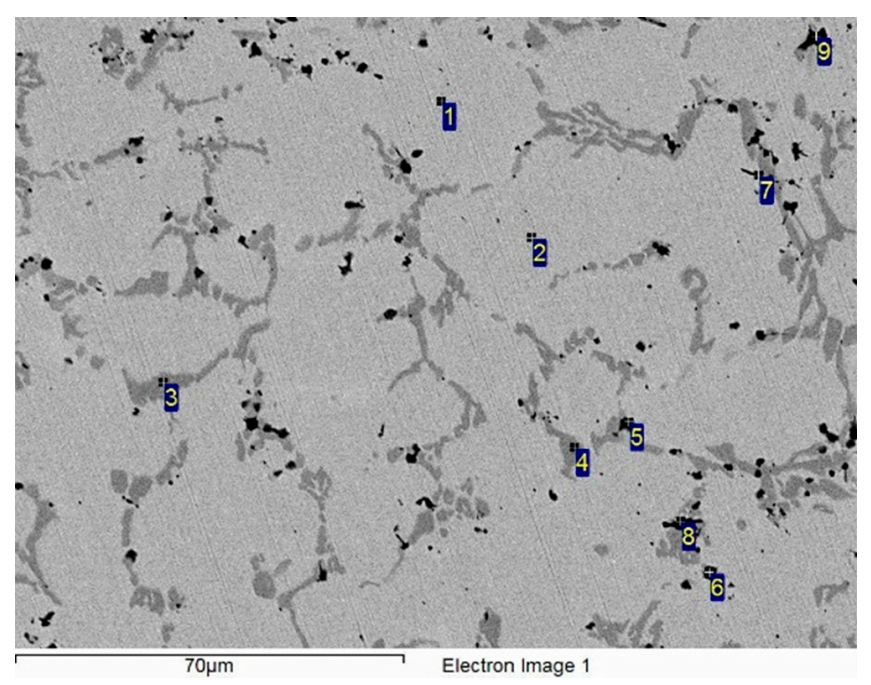

Fig. 4. Steel microstructure. Initial mixture: Basic mixture (BM) $-88.3 ; X-5.0 ; Y-6.7$.

Table 4. Composition of steel structural components (Fig. 4). Initial mixture: $\mathrm{BM}-88.3 ; X-5.0 ; Y-6.7$.

\begin{tabular}{|c|c|c|c|c|c|c|c|}
\hline \multirow{2}{*}{$№$} & \multicolumn{7}{|c|}{ Composition, wt \% } \\
\cline { 2 - 8 } & $\mathrm{Fe}$ & $\mathrm{Cr}$ & $\mathrm{Mn}$ & $\mathrm{Ni}$ & $\mathrm{Mo}$ & $\mathrm{V}$ & $\mathrm{Si}$ \\
\hline 1 & 66.1 & 17.0 & 6.5 & 9.5 & 0.4 & 0 & 0.5 \\
\hline 2 & 65.6 & 16.8 & 6.5 & 9.8 & 0.7 & 0.2 & 0.4 \\
\hline 3 & 24.2 & 67.2 & 4.9 & 0.3 & 2.0 & 1.3 & 0.1 \\
\hline 4 & 23.3 & 66.9 & 4.8 & 0.6 & 2.8 & 1.5 & 0.1 \\
\hline 5 & 16.3 & 6.0 & 36.4 & 1.7 & 39.5 & 0 & 0.1 \\
\hline 6 & 13.2 & 24.7 & 24.3 & 1.6 & 35.2 & 1.0 & 0 \\
\hline 7 & 43.5 & 26.6 & 11.6 & 6.7 & 10.7 & 0.5 & 0.4 \\
\hline 8 & 10.3 & 8.7 & 38.6 & 0.6 & 41.7 & 0 & 0.1 \\
\hline 9 & 9.3 & 15.8 & 31.3 & 1.0 & 42.0 & 0.6 & 0 \\
\hline
\end{tabular}

the steel vary slightly and are close to the calculated values. According to X-ray phase analysis, steel has $\gamma$-Fe lattice (Fig. 2). The displacement of the peaks and their broadening indicate the dissolution of the alloying elements in $\gamma$-Fe.

Steel has a grain structure with narrow grain boundaries. Point inclusions concentrated in the grains and at the boundaries were also detected (Figs. 3, 4). The analysis of the elemental distribution (Fig. 3) and structural components composition (Fig. 4, Table 4) proves that the steel base is formed by $\mathrm{Cr}, \mathrm{Mn}$ and Ni solution in Fe, the narrow boundaries between the grains are formed by Fe, Mn, Mo and $\mathrm{V}$ solution in $\mathrm{Cr}$. The point inclusions mainly contain Mn and Mo.

\section{Discussion}

Considering the ideas developed earlier in the study of SHSmetallurgy $[18,19]$, we can present the following dynamics of nitrogen steel production. Chemical transformation proceeds in the combustion front of $\mathrm{Fe}_{2} \mathrm{O}_{3} / \mathrm{MnO} / \mathrm{NiO} /$ $\mathrm{MoO}_{3} / \mathrm{V}_{2} \mathrm{O}_{5} / \mathrm{SiO}_{2} / \mathrm{Al} / \mathrm{Cr} / \mathrm{Cr}_{2} \mathrm{~N}$ mixture. The products of the chemical transformation are $\mathrm{Fe} / \mathrm{Cr} / \mathrm{Mn} / \mathrm{Ni} / \mathrm{Mo} / \mathrm{V} / \mathrm{Si} / \mathrm{N}$ steel and slag $\left(\mathrm{Al}_{2} \mathrm{O}_{3}\right)$. The reaction high thermal effect makes it possible to achieve the combustion temperature exceeding the melting point of steel and slag. A two-phase melt is formed from the melt of the combustion products, in which the slag forms a continuous medium, and the steel in the form of droplets is distributed in it. As the combustion front moves, the height of the melt layer increases. A temperature gradient is formed in the layer. So, gravitational convection develops under the influence of gravitation (or overloading). The convective motion speed is determined by Grashof number. According to the criterion, with an increase in the temperature gradient and overloading, the convective motion speed increases. The convective motion above the combustion front leads to intensive mixing of the melt, more complete chemical transformation of the initial mixture, and formation of a uniform composition of the combustion products (droplets of steel and slag).

When the combustion is completed, the intensity of the convective motion decreases and gravity separation of the combustion products takes place. Under optimal conditions, the completeness of gravity separation is close to the calculated value and after cooling and crystallization, a twolayer product, steel and slag, is formed.

According to the experiments, the obtained steels show a deficit in $\mathrm{Mn}$ and $\mathrm{N}$ in comparison with the calculated values (Table 2 and Fig. 1). Comparison of the combustion temperature $\left(T_{c}>3000 \mathrm{~K}\right)$ and the boiling point $\left(T_{\mathrm{b}} \sim 2100 \mathrm{~K}\right)$ proves that the reason of the deficit in $\mathrm{Mn}$ is the removal of its vapor from the melt of the combustion products. The reason for that in $\mathrm{N}$ is the removal of the super-equilibrium content of steel. Other sources of gas evolution from the melt are $\mathrm{Al}$ suboxides and the metal vapors contained in the steel.

The formation of gases during combustion and their subsequent escape from the melt leads to the scattering of the combustion products, as well as their further mixing. The mechanism for suppressing the scattering by overloading and its effect on the combustion process was considered in detail in previous publications $[18,19]$.

\section{Conclusions}

The method of centrifugal SHS-metallurgy can be used for obtaining alloyed steels with nitrogen content of up to $0.3-0.4 \mathrm{wt} \%$.

Overloading suppresses scattering at combustion of highexothermicmixture $\mathrm{Fe}_{2} \mathrm{O}_{3} / \mathrm{MnO} / \mathrm{NiO} / \mathrm{MoO}_{3} / \mathrm{V}_{2} \mathrm{O}_{5} / \mathrm{SiO}_{2} / \mathrm{Al} / \mathrm{Cr}$ with $\mathrm{Cr}_{2} \mathrm{~N}$, allows separating the combustion products, steel and slag $\left(\mathrm{Al}_{2} \mathrm{O}_{3}\right)$, and provides high yield of the target product into the ingot.

Gravitational convection of the two-phase melt above the combustion front and bubbling of the gaseous products ensure intensive mixing, high completeness of the chemical transformation of the initial mixture, and the uniform composition of the steel.

Acknowledgement. To realize the research, the equipment at the ISMAN Center of Shared Cervices was used. The research was carried out with the financial support of the RAS program, within Scientific Project PrAN № 55. 


\section{References}

1. Yu. A. Shulte. Cold-resistant steels. Moscow, Metallurgiya (1970) 223 p. (in Russian)

2. V.P. Larionov, V.R. Kuzmin, O.I. Sleptsov, A. M. Bolshakova at als. Cold resistance of materials and construction elements: results and perspectives. Strength, operation life and diagnostics of metal construction elements. Novosibirsk, Nauka (2005) 290 p. (in Russian)

3. O. A. Bannykh, V. M. Blinov, M. V. Kostina. High-nitrogen corrosion-resistant austenite steels for high-rel items. 60-th anniversary of Baikov Institute of Metallurgy and Materials Science, Book of abstracts. Ed. N. P. Lyakishev. Moscow, ELIZ (1998) p. 192. (in Russian)

4. O.A. Bannykh, V.M. Blinov. Development of highnitrogen austenite and martensitic corrosion-resistant steels for high-rel items. Baikov Institute of Metallurgy and Materials Science - 75-th Anniversary: Book of abstracts. Ed. K. A. Solntsev. Moscow, Interkontakt Nauka (2013) p. 204. (in Russian)

5. O. A. Bannykh, V.M. Blinov, M. V. Kostina, E. V. Blinov, S. O. Muradyan. Materialy v mashinostroenii. 89(2), 67 (2014). (in Russian)

6. E. A. Goli-Oglu, Z. Greisen, Yu.A Bokachev. Chernye Metally. 6, 53 (2018). (in Russian)

7. L.S. Derevyagina, A.I. Gordienko, Y.I. Pochivalov, A.S. Smirnova. Physics of Metals and Metallography. 119(1), 83 (2018).

8. D.V. Kudashov, E.S. Mursenkov, P.P. Stepanov, G. V. Semernin, V. V. Kislica, S. A. Somov, A. V. Lozovskiy, M. R. Jarmuhametov. Metallurgist. 61(7-8), 656 (2017). DOI: $10.1007 / \mathrm{s} 11015-017-0547-0$
9. I.P. Shabalov, V.G. Filippov, O.N. Chevskaya, L. A. Baeva. Metallurgist. 61(5-6), 463 (2017). DOI: $10.1007 / \mathrm{s} 11015-017-0518-5$

10. A.V. Chervonnyi, V.V. Naumenko, A.V. Muntin, L. I. Efron, O.N. Chevskaya, I. V. Lyasotskii. Metallurgist. 60(9-10), 1038 (2017). DOI: 10.1007/s11015-017-0405-0

11. P. Layus, P. Kah, A. Zisman, M. Pirinen, S. Golosienko. International Journal of Mechanical and Materials Engineering. 11,2(2016).DOI: 10.1186/s40712-016-0055-1

12. S.A. Krylov, A.G. Evgenov, A.I. Scherbakov, A. A. Makarov. Trudy VIAM. 41(5), 1 (2016). (in Russian)

13. Ts. V. Rashev. High-nitrogen steels. Metallurgy under pressure. Sofia, Prof. Marin Drinov (1995) 272 p. (in Russian)

14. I.V. Sapegina, G.A. Dorofeev, M.I. Mokrushina, B.E. Pushkarev, V.I. Ladyanov. Letters on Materials. $\quad 7(2), \quad 137 \quad$ (2017). (in Russian) DOI: $10.22226 / 2410-3535-2017-2-137-140$

15. A. G. Merzhanov. Solid flame combustion. Chergolovka, Izd. ISMAN (2000) 239 p. (in Russian)

16. M. Kh. Ziatdinov. Metallurg. (12), 50 (2008). (in Russian)

17. V.I. Yukhvid. Pure and Appl. Chem. 64(7), 977 (1992).

18. V.I. Yukhvid. Tsvetnaya metallurgiya. 5, 62 (2006). (in Russian)

19. E. A. Levashov, A.S. Rogachev, V.V. Kurbatkina, Yu. M. Maksimov, V.I. Yukhvid. Promising materials and technologies of self-propagating high-temperature synthesis. Moscow, MISIS (2011) 378 p. (in Russian)

20. V.I. Yukhvid, V.A. Gorshkov, V.N. Borsch, P. A. Miloserdov, N.V. Sachkova, M.I. Alymov. Letters on Materials. 7(3), 332 (2017). (in Russian) DOI: $10.22226 / 2410-3535-2017-3-332-336$ 